\title{
OPTICAL MONITORING AND CONTROL OF DRYing Processes
}

\author{
STURM, B. \& HOFACKER, W.
}

Abstract: Colour is one of the most important criteria for the quality of food products. It does not only influence its subjective appreciation by the consumer but can also be used for the determination of quantitative quality criteria which depend on the drying process. Changes in shape and development of temperature are further criteria for the evaluation of the drying process.

The paper gives a synopsis of the techniques of measurement and quantification methods for colour, two dimensional shrinkage, infrared thermometry and control strategies based on data gained using methods of non destructive measurement. Special emphasis is given to the use of low cost hardware available as digital equipment and to the possibility of continuous measurement. The different methods of colour designation in terms of RGB, XYZ or $L^{*} a^{*} b^{*}$-values are discussed. It is shown, that information relevant for the control of the product quality can be derived from the image data.

Key words: colourimetry, imaging, monitoring, drying, infrared thermography
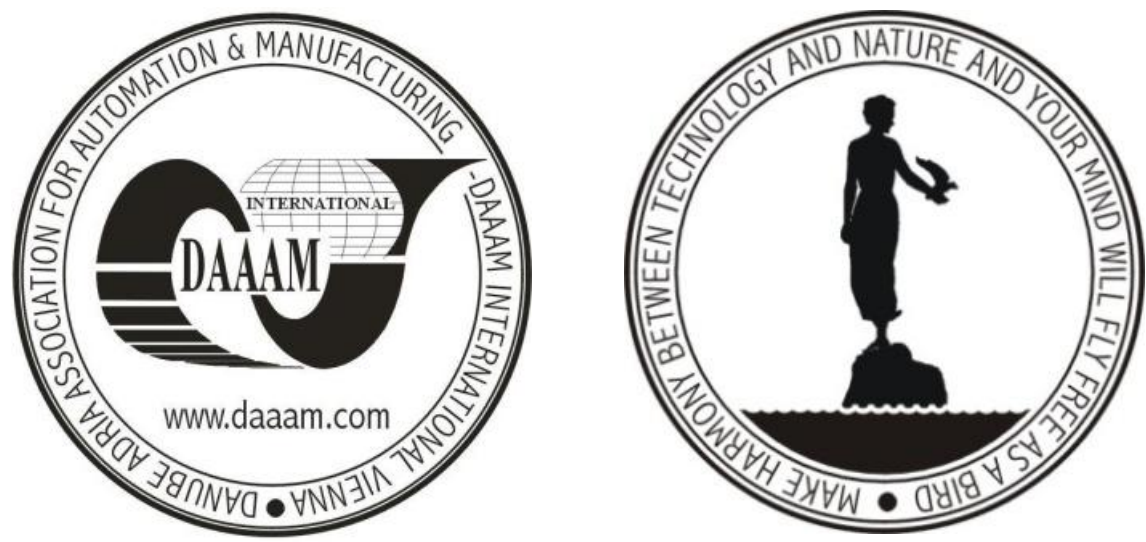

Authors' data: Dipl.-Ing. (FH) Sturm, B[arbara] M.Eng.; Prof. Dr.-Ing. Hofacker, W[erner], Hochschule Konstanz, Technik, Wirtschaft und Gestaltung, Brauneggerstasse 55, 78462, Konstanz, Germany, bstrurm@htwg-konstanz.de, hofacker@htwg-konstanz.de

This Publication has to be referred as: Sturm, B[arbara] \& Hofacker, W[erner] (2009). Optical Monitoring and Control of Drying Processes, Chapter 50 in DAAAM International Scientific Book 2009, pp. 501-512, B. Katalinic (Ed.), Published by DAAAM International, ISBN 978-3-901509-69-8, ISSN 1726-9687, Vienna, Austria DOI: $10.2507 /$ daaam.scibook.2009.50 